\title{
A Novel Approach to Tradition: Torres Strait Islanders and Ion Idriess
}

\author{
Maureen Fuary \\ Anthropology and Archaeology \\ James Cook University
}

This paper considers the significance of the novel Drums of Mer (1941) in contemporary Torres Strait Islanders' lives. Its use as narrative by many Islanders today constitutes one means by which men especially have come to know themselves, white others, and their past. In particular, I explore the ways in which this story appeals to and is appealed to by Yam Island people. Contrary to literary deconstructions of Idriess's representations of Aboriginal and Torres Strait Islander people, my paper argues that in seriously attending to Torres Strait readings of Drums of Mer we can see that for contemporary Islander readers, it is not themselves who are other but rather the white protagonists.

I employ Said's (1994) notion of 'cultural overlap' and de Certeau's (1988) understandings of reading and writing as 'everyday practices' to frame my analysis of the differing impacts of the historical novel, Drums of Mer, and the Reports of the Cambridge Anthropological Expedition to Torres Straits. It is through story telling that Yam Island selves are placed in the past and the present, and in Idriess's memorable story a similar effect is achieved. In his novel approach, the past becomes his-story, a romanticised refraction of the Reports. Unlike the Reports, this novel is a sensual rendering of a Torres Strait past, and at this level it operates as a mnemonic device for Yam Island people, triggering memories and the imagination through the senses. This Torres Strait Islander detour by way of a past via a story, can be understood as a means by which Yam Island people continue to actively produce powerful images of themselves, for both themselves and for others.

... stories are at the heart of what explorers and novelists say about strange regions of the world; they also become the method colonized people use to assert their own identity and the existence of their own history. (Said 1994: xiii)

Torres Strait Islander people live in a number of mainland Australian towns and cities and on a relatively small number of islands in the Torres Strait. Despite the long-term

THE AUSTRALIAN JOURNAL OF ANTHROPOLOGY, 1997, 8:3, 247-258 
effects of colonialism since the beginning of the 19th century, Torres Strait Island people continue to recognise themselves as unique peoples with their own particular cultural characteristics associated with belonging to specific clusters of islands (Top Western, Western, Eastern and Central). For generations now Torres Strait Islanders have existed in and contributed to a rapidly changing social and political world. People draw their strength, confidence, feelings of belonging and well-being from the past, and from their identity as Islanders from particular islands. Islanders' transformation from a majority group to a minority group through the processes of colonialism has provided the context and impetus for the development and maintenance of their contemporary expressions of cultural identity. It is from their strong sense of belonging, which is continually asserted and reaffirmed, that Island people actively encounter and embrace the contemporary world.

In this paper I focus on the responses of one group of Central Island people (the Kulkalgal of Yam Island) and some Eastern Island people (the Meriam or Murray Islanders), to a mid-20th century novel set in the early 19th century. ${ }^{1}$ This novel is centred on both groups of people and draws heavily upon a set of reports on anthropological work conducted in the region at the turn of the century. In particular I explore the ways in which Ion Idriess' representations of Torres Strait Islander people in the popular novel Drums of $\operatorname{Mer}(1941)$, have gained a measure of authority and authenticity among some Torres Strait Islander readers. While I am initially interested in how this novel is considered by Yam Island people in particular, the appeal of Idriess would appear to be more broadly based throughout the Torres Strait region. In teasing out the ways in which this novel continues to play a significant role in some Torres Strait Islanders' perceptions and understandings of their respective pasts, I begin to interrogate the generalised impact of Idriess, as historical novelist, in contrast to the very specialised impact of Alfred Cort Haddon, as anthropologist. What is it about Idriess's particularly colourful embellishment of known historical events and characters, drawn essentially from Haddon's Reports of the Cambridge Anthropological Expedition to Torres Strait ${ }^{2}$ which renders it a meaningful and authentic representation of tradition for some Torres Strait Islander people? How is it that a novelist who ambivalently assumes white European superiority while asserting the supernatural power and primal physicality of black Torres Strait Islanders, is drawn upon so confidently by Torres Strait Islander people?

Rather than dismantling the text of Drums of Mer, my intention in this paper is to resurrect it, and in so doing demonstrate that it constitutes an important document through which many Torres Strait Islander people, especially men, have come to know themselves, white others, and their past. Unlike literature-based deconstructions of Idriess and in particular those critiquing his representations of Aboriginal and Torres Strait Islander

1. Bipo taym ('before time') is the Islander pidgin phrase referring to the period before colonialism became a reality, and it symbolises an epoch of physical and supernatural power. This is the time frame within which the Idriess novel is set. During this era there were a significant number of European shipwrecks and associated castaways on some of the islands.

2. Hereafter referred to as The Reports. 
people (see Shoemaker 1992; Dixon 1996), my paper argues that in seriously attending to Torres Strait readings of Drums of Mer we can see that for contemporary Torres Strait readers, it is not themselves who are other but rather the white protagonists. While of course it is not the prime means by which Torres Strait Island identities are constructed (Fuary 1991, 1992, 1993; see also Fitzpatrick-Nietschmann 1980; Beckett 1987), Drums of Mer does, however, continue to play a significant role as an important written document, as a representation of tradition, to which many Islanders consistently refer. Hence I do not regard this text as problematic but consider its contemporary use as narrative by Yam Island people in particular, as one of the many means by which they articulate to themselves and to others who they are and from where they have come.

\begin{abstract}
... to ignore or otherwise discount the overlapping experience . . . the interdependence of cultural terrains in which colonizer and colonized co-existed and battled each other through projections as well as rival geographies, narratives, and histories, is to miss what is essential about the world in the past century. (Said 1994:xxii-xxiii)
\end{abstract}

While finding Said's notion of cultural overlap useful, I suggest that in this instance the particular narratives of Drums of Mer and The Reports, upon which Torres Strait Islanders and non-Islanders alike are drawing as representations of Torres Strait Islander culture and history on the frontiers of colonialism, are not so much competing or rival narratives, but can be more constructively approached as one narrative (Drums of Mer) being the romanticised refraction of the other (The Reports).

What is especially interesting to me is why some Yam Island people, especially men, have encouraged me on a number of occasions since I first began research in their community in 1980 , to defer to the authority of Idriess. For instance, there are regular references to Drums of Mer in my fieldnotes. This entry, recorded during my first days on Yam Island clearly illustrates my initial incredulity at Idriess' authority:

FNB16:55 20/1/1980

Yesterday afternoon X gave me Ion Idriess' Drums of Mer to read. He doesn't realise it's a novel. Believes it is fact. It talks about Kebisu. ${ }^{3}$

What I find interesting in looking back at these comments is that they were made during the first few days of my stay on Yam Island when people were trying to fully comprehend what I was doing there. What is more, there is an obvious preoccupation with 'Truth' on my part ('Believes it is fact'). As nascent anthropologist undertaking fieldwork for the first time, my horror at being referred to a novel as the site of Yam Island tradition, is exemplified in the above excerpt. Such a referral (and implicit deferral) to the authority of Idriess, as the man who had already documented Yam Island culture, clearly undermined my sense of the research I was about to undertake. In my knee-jerk reaction I too readily aligned historico-cultural truth with anthropology and fiction with the novel, hence retaining a niche for myself and my work.

3 Kebisu, the great great grandfather of $\mathrm{X}$ is a legendary Yam-Tudu heroic chief. He is seen to have exerted tremendous power throughout the region in his dealings with other Torres Strait peoples, Papuans and Europeans alike. To Yam Island people Kebisu signifies their pre-colonial strength and power. 
Much later in time and in my practice as anthropologist, I have been reminded on several occasions, most recently in 1996 and 1997, of the contemporary salience of this novel. In the first instance a man raised on the Australian mainland and engaged in a research project on Yam Island, the place of his forebears, read as much Idriess as he could so as to thoroughly familiarise himself with Yam Island cultural history as preparation prior to visiting the island.

The second event which caught my attention was an interview on $\mathrm{ABC}$ radio with Raymond Blanco, the Sydney based Artistic Director of the Aboriginal and Islander Dance Theatre, discussing his dance piece, Drums of Mer, performed on Thursday Island for the 1996 Torres Strait Cultural Festival. With relatives in the eastern islands, Blanco explained that he had devised a danced history of the Torres Strait after having read Drums of Mer, and marvelled at what was contained in the text, stating that there was cultural material in the book that even he didn't know about. In so saying, Blanco publicly endorsed the authority of Idriess' representations of Torres Strait culture and history in contrast to his own phenomenological understandings.

In the program for the Sydney season of production, Blanco states:

In deciding to stage this production, many areas had to be covered in hours of research. The discovery of the book by the late Ian [sic] Idriess was in many ways a blessing and a burden. Discussions with traditional consultants . . . uncovered areas which are deemed taboo. This proved a tightrope walk between Traditional Law and western law... . My first priority is to not offend the elders in any way without sacrificing the intention of the dance work. Tonights [sic] performance is inspired by the highly descriptive and colourful language used in Idriess' book. However, it has become necessary to bring the dance works to life. (Aboriginal and Islander Dance Theatre 1996)

The dance was constructed around 8 of the 32 chapters in Drums of Mer. The bringing of this text to a particular life on stages in Sydney and on Thursday Island, requires its own analysis particularly in relation to issues such as performance, theatre, movement, engagement between dancers and audience, and audience response. This analysis cannot be undertaken here, although it is worth noting that, following Taussig's (1991) work on mimesis, the dance could be productively seen as a response to and further representation of the original, that is to say, Haddon's Reports and the derivative, Idriess's Drums of Mer.

In Sharp's (1996) analysis of the Murray Island Land Case ${ }^{4}$ she referred to the role played by Idriess' novel in terms of Meriam understandings of their past. When I

4. In 1879 all the Torres Strait islands had been placed under Queensland's jurisdiction and it was not until 1984 that the islands ceased to be reserves. By the late 1980s all the outer island communities except Murray Island had accepted the Deeds of Grant in Trust giving them leases to their land and not the inalienable freehold title they had requested in 1981. Five Murray Island people led by Koiki Mabo claimed traditional title and prior ownership of their islands in the High Court of Australia and the Supreme Court of Queensland. In 1992 (after ten years) the High Court found in favour of the litigants, recognising that their title to land and their legal system had existed prior to colonisation and had continued subsequent to colonisation. This finding represented a landmark decision invalidating the premise of terra nullius, a term used by the British Colony to justify continued occupation of the Australian continent. 
presented an earlier version of this article at the Australian Anthropological Society in 1996, Sharp commented that the Meriam people had expressed to her their wish to make a film about themselves called 'Drums of Mer' (Sharp pers. comm. 1996). Interestingly, in both these instances referred to by Sharp, the Meriam can be seen to be articulating a resolute belief and confidence in the authenticity of Idriess' representation of their past, and its resonating significance in the present. It is almost as if the creative authorship and embellishment of Idriess has been erased, with the text being regarded as a Murray Island text, a Meriam representation of themselves.

The most recent exemplifications of the contemporary salience of this text in the construction of Yam Island notions of their cultural traditions and history occurred in 1997, when I undertook a trip to the island. On this occasion an older male asked if I could send him a photograph of an ancestor who appears in some editions of the novel. A few days later, in a community workshop concerning the collaborative work I am engaged in with the Yam Island Community Heritage Committee, one of the committee members explained to other members of the community, that the publication arising out of the work of Haddon and his colleagues was a book, which she tentatively suggested was called Drums of Mer.

This novel then continues to inform Yam Island people in a way in which the Reports do not. Certainly, Yam Island people are not familiar with the 6 volume Reports. Idriess is known and has been read, whereas Haddon et al. are only recently becoming known. As Beckett (pers. comm.) had pointed out, The Reports were almost impossible to acquire until they were reprinted in the 1970s, whereas Drums of Mer has been relatively cheap and easy to obtain since the 1950s. It would seem that the role of contemporary anthropologists has been crucial in bringing the Reports to light on specific islands on which they have worked in the Torres Strait, whereas the popularity of Drums of Mer has not required the active sponsorship of any other promoter. In a sense it appears to have promoted itself. Idriess's text is tangible and remembered: at some point or other, most adults and adolescents on Yam Island have at least glimpsed Drums of Mer.

Rather than imagining these texts, Drums of Mer and the Reports, as competing representations of 19 th century Torres Strait, in which one is regarded as predominantly truth and the other as predominantly fiction, we can see that the Idriess text can exist only in relation to the other. Idriess was indebted to the Cambridge Anthropological Expedition Reports. He presents some of the textual and photographic material collected by the expedition, and it is in this sense that his book is most obviously derivative. Like Haddon et al. before him, Idriess also drew upon the knowledge, experience and interests of the missionary MacFarlane, as intermediary, to both augment his material and to give him entree into the Torres Strait.

This story is in all essentials historical fact. . . Ethnologically, too, the story is correct. Here, I am greatly indebted to the splendid Reports of the Cambridge Anthropological Expedition to Torres Strait and to that living mine of Torres Strait ethnological lore the Rev. W. H. MacFarlane . . who put me in personal touch with the Island historians. (Idriess 1941:ix)

Indeed, in the 1941 edition it is MacFarlane who contributes the Foreword: 
To one who for a good many years has lived among the tropic isles of Torres Strait, and whose constant regret has been that their romantic attractiveness is so little known ... the Drums of Mer comes with very strong appeal. There are some who may think that $\mathrm{Mr}$ Idriess is giving us simply an imaginative picture, but the author has travelled the Strait with the discerning eye and contemplative soul of the artist who is satisfied only with first-hand colour, and who, while blending history and romance with subtle skill, at the same time keeps within the region of fact. (MacFarlane in Idriess 1941:v. My emphases)

To label Drums of Mer essentially derivative, would severely limit the possibilities for our understanding. Rather, it is the way in which Idriess blends and blurs, manoeuvring himself and his characters 'within the region of fact', that the full impact of his narration is felt.

Idriess presents the substance of the Reports in another genre, the historical novel, brimming with romance and adventure, while at the same time authenticating it with the inclusion of photographs of known individuals, places, maps, cultural objects ${ }^{5}$ and regular references to explorers, such as D'Albertis. These inclusions add to the degree of uncertainty and slippage, for it is never entirely clear to the reader as to what is purely imaginative in the plot as opposed to more firmly realistic. This is not just the tension between reading a novel constructed around a particular aesthetic, as opposed to reading reports specifically designed as scientific, but rather constitutes a very peculiar dynamic which has necessarily emerged from the conflation of two such genres in a single text. ${ }^{6}$

To add to this skilful blurring of artistic and historical conventions, Idriess' voice intervenes or interrupts at regular intervals, bringing the reading audience back to Idriess' present, at the time of his writing. In this device of collapsing the 20th century into the 19 th century, Idriess directly addresses the reader, drawing upon her/his familiarity with the Torres Strait. Idriess also has the hero, a white male castaway, Jakara, regularly anticipating the future with references to well-documented historical events, such as the establishment of an administrative centre on Thursday Island by Lt. Chester which occurred some time after the time frame of the novel.

Part of the success of this novel stems from the way in which Idriess engages in story telling (yan stori). His story-telling is memorable,$^{7}$ and the recounting of events and persons in the past closely approximates the traditions of Yam Island story-telling, in this case, the recounting of history (see White 1973). Here I am thinking of history not as a

5. In the 1941 edition, there is one map, several photographs of places and objects including funerary poles, skulls, masks, weapons and sites of significance which originally appeared in The Reports, several drawings of objects (originating in The Reports), and photographs of well known individuals from Mer and Yam-Tudu Islands (also originating in The Reports). These materials are supplemented with a number of other photographs.

6. For an example of how novel and ethnology may operate in dialogue as opposed to one being collapsed into the other, see Gottlieb and Graham (1993). In this text the anthropologist and her novelist husband represent the 'same' event in consecutive chapters which speak to each other.

7. For a discussion of Idreiss' ability as a story-teller, see Roderick (1947), Barker (1993), Ruhen (1979) and Elvey (1995). 
temporal operation but, as Biersack (pers. comm.) has suggested, as more specifically an association between place, action and people.

It is through yan stori that Yam Island selves are placed in the past and the present (Fuary 1991), and in Idriess' story telling the same effect is achieved. In his novel approach, the past becomes his-story, a romanticised refraction of the Reports. While this novel isn't about Yam Island, there are enough references to significant places, people and events to enable the Yam Island reader to say 'It's all in here', especially in relation to their perceptions of pre-invasion masculine identity, and the predominating role of warfare. As I have argued elsewhere (Fuary 1991:320), the essential power that Yam Island men exerted in the distant past as warriors, ritual specialists and headhunters has been supplanted by powerful beliefs and stories about the past which continue to affect and inform their present. Following Harrison, I would like to suggest that like violence per $s e$, stories about pre-invasion masculine power, strength and violence such as those appearing in Drums of Mer can be seen as a 'range of symbolic practices by means of which groups act to constitute themselves within the system of relationships encompassing them' (Harrison 1993:14).

Palsson (1994:6-8) has noted that during the 19th century the 'semi-ethnographic novels' took over from 'the fabulous travel account', and that it was the device of mixing 'historical realities with imaginary events' which enabled the difference between 'them' and 'us' to be exaggerated. This is certainly an effect of Drums of Mer, both for us and for Torres Strait Islander readers. I would argue, however, that this divide is employed by Torres Strait readers to construct the white protagonists as 'them' and 'other', and the Torres Strait protagonists as 'us' and 'self'.

The representation of Torres Strait Islander men as fierce, beautifully bodied, preoccupied with magical power and warfare, as a world unto themselves, albeit a world on the cusp of dramatic social change through the increasing incursion of powerful others into their domain, is an image which I suggest delights a Yam Islander readership, particularly a male readership. Through a very specific and active reading, they can see themselves and their Meriam counterparts as potent and impenetrable, ambivalently engaged in resisting colonial incursions yet at the same time desiring white knowledge and power (see Bhabha 1984).

Although most of the action takes place on Mer, I suspect Yam Islanders ${ }^{8}$ see themselves as central subjects in this story, for Kebisu, their iconic chief is engaged in power plays with C'Zarcke the awesome Meriam priest, ${ }^{9}$ with their Central Island neighbours on Puruma and Gebar, and with the whites. Though Idriess eventually renders Kebisu impotent in the face of change, this is a reading I do not think Yam Island people especially attend to. The island of Tudu is never far away, and the inclusion of a photograph of Maino, a descendant of Kebisu, connects this story-time of Kebisu to the time of now (see de Certeau 1988:77-90).

8. The descendants of the Yam-Tudu people have not been living on Tudu since the turn of the century (see Fuary 1991, 1993).

9. The powerful priests referred to by Idriess were the hereditary cult officials of the MaloBomai cult who wielded the most authority on Mer (Murray Island). 
In this story Yam Islanders, through their ancestral heroes, are cast as savage yet sensitive selves against savage yet fundamentally weak others in the form of two white castaways, a male and a female. Jakara, the male castaway was so terrified of the power of the zogo le, the local religious specialists, and of the possibility of being forced to do the 'dance of death', that he escaped the island of Mer. And yet, this 'semi-ethnographic' novel does more than exaggerate difference. It is artefactual to this genre that the Torres Strait people of the Cambridge Reports are transformed into individuals in the novel, through having life breathed into them in a way which is lacking in the Reports. This text, unlike the Cambridge Reports, evokes the past through the senses, and celebrates it. Idriess fills out the known and knowable characters with imagined intentions, emotions, powers and sexuality, connecting them with similar and dissimilar others in time and place, in a plot which borrows from the Reports and from his own imaginative repertoire. Individuals and events are brought into being, embodied and emplaced within knowable, remembered, emotional, social and geographical terrains, a social landscape of action and meaning in which members of the contemporary Yam Island community are infinitely comfortable and at home. Idriess brings into being named and known heroes who engage in everyday practices in a named and known landscape and seascape. This spatial, temporal and emotional anchoring of the novel's characters, black and white, authenticates the tale:

\begin{abstract}
Kebisu stood out big even among the striking men there [on Mer], his stature emphasized by enormous shoulder muscles, his limbs long and powerful, his bearing sheer untamed arrogance, his face unexpectedly pleasing because of his boyish happiness which occasionally lightened the grim jaw and broad, savage cheeks. The full brow was noticeable between the ringlets that fell upon his shoulders, arranged to hide the fact that the left ear was missing, bitten off in a fight. When he was angered, Kebisu's face flushed red, particularly around that part where the ear had been; and at that ominous sign his savage warriors grew subdued and mild. Worthily accounted the brainiest chief of the Island nations, this man was possessed of unbridled ferocity, and yet he had been known to cry because he could not relieve a child in pain. Apart from the supermen of culture who had come with the Bomai-Malu, and of C'Zarcke in the present age, this man was the greatest organizing genius that the Torres Strait Islands had ever known. Both for war and for trade he had made his own tiny island of Tutu [Tudu] the key position for all commerce and war that came from far down the Australian coast, right across the length and breadth of the Strait, to New Guinea's shores. Nothing could come, nothing could pass, nothing could go across the seas, without paying heavy tribute to Kebisu of Tutu on his tiny sandbank ... His men were better fighters than those of Mer. He had an alliance with the Eastern Group because of their importance for trade. Had it not been for the supernatural power which C'Zarcke wielded over all the Strait, Kebisu would long ago have taken Mer by force. (Idriess 1941:51-2)
\end{abstract}

It is in the bringing back home of some of the data from the Reports, that Drums of Mer finds its mark for Torres Strait readers, and this helps in some measure to account for the referential and authoritative position the text continues to occupy on Yam Island. The full bodied drama is brought to life in the novel in ways in which it can never be realised in the dry, disembodied and essentially non-dramatic Reports. Drums of Mer is a sensual rendering of the Torres Strait past, especially the early 19th century interactions between 
Torres Strait Islander people and white others, and at this level it operates as a mnemonic device, triggering memories and the imagination through the senses.

This technique of playing with well known events and figures, by creating a melodramatic and fantastic universe within which these events are seen to unfold in a particular place on the frontiers of change, has also worked extremely well for Idriess' non-Torres Strait Islander readers (Dixon 1996; Shoemaker 1992; Barker 1993; Ruhen 1979). The interwar period, and especially during the political and economic turmoil of the 1920s and 1930s, was when the essentially urban Australian population was invited to 'share vicariously in a common pioneering past' (Kiernan 1988:272). It was during this period that the major publishing house in Australia, Angus and Roberston, published Idriess' books at the average rate of one book per year (Nile and Walker 1988). Idriess deliberately situated himself, his reader and his characters within a framework of great adventure and romance, collapsing in some senses the gap between reader and author. ${ }^{10} \mathrm{As}$ a 'travelling raconteur' (Shoemaker 1992:92) with the gift of storytelling, Idriess located himself in the places in which he crafted his tales, thereby transporting his readers to worlds they were unlikely to ever visit:

... the public who liked my books, each year they could depend on getting life in some wild part of Australia they knew nothing about and was quite different from the other parts. That was one of the secrets of my success, but the writers who wrote up the reviews never seemed to tumble it. (Idriess in Foster 1991:80)

Shunned by literary critics at the time, many of Idriess' novels were bestsellers, and Shoemaker (1992:58) has observed that the inter-war period in Australian literature belonged to Idriess. As recently as the 1980 s he remained the single bestselling author for Angus and Robertson, with over 3 million copies of his books having been sold (Shoemaker 1992:54-5).

Although Idriess exhibits a highly ambivalent approach towards Torres Strait Islander people in his writing (see Shoemaker 1992 in relation to Aboriginal Australia), it is in such a space of authorial ambivalence that a wealth of readings and interpretations become possible, thus freeing the text from a single authoritative reading. Islanders in the text can read themselves as standing outside and in opposition to European society. It is in recognising this that contemporary Torres Strait Islanders are able to adopt a stance from which they are able to celebrate and signify their otherness by asserting their selfhood.

It is in this meta-narrative of fixed places and labile stories that Idriess familiarises, temporalises, spatialises, indivualises, and romanticises a particular era in Torres Strait history drawn from the Cambridge Reports. This particular past with these places, these people and these practices as spoken about by Idriess constitute an important point of reference for Yam Island people. In Idriess' story, Yam Island people can see themselves as operating in opposition to an increasing presence of white invaders from the sea who

10. See Strathern (1987) on the modernist anthropological project which established a distance between the anthropologist as author and authority, the subjects and the audience. Her discussion of the differing literary and anthropological effects of Frazer (as pre-modernist) and Malinowski (as modernist) might also assist in our understanding how such relatively dry writers as Rivers and Haddon have been rendered somewhat invisible in anthropology's own sense of its past and its heroes. 
are powerful yet essentially weak others, while at the same time being intrigued by and desiring some of the obvious power of the whites, and of having actively incorporated some of the individuals into their own society, but on their own terms. Jakara, the handsome white male residing on Mer, and Eyes of the Sea, the beautiful white female residing on Tudu, represent two different expressions of the castaway experience, the male and female, the resistant and the respectful. ${ }^{11}$ Here again, we encounter ambivalence, opening up a wealth of possible readings of these two characters alone. Taking de Certeau's (1988) distinction between space and place, tactics and strategies as a possible starting point, and looking at writing and reading as 'everyday practices', we might think of the employment of this story as a means by which Torres Strait Island people as (generally) non-powerful members of Australian society, are able to 'trace out the ruses of their own interests and desires that are neither determined nor captured by the systems in which they develop' (de Certeau 1988:xviii).

We can also see Idriess engaging in the tactics of manipulating an authoritative representation of Torres Strait culture and tradition (in the Reports) and deploying it into a story with its own 'errant trajectory' (de Certeau 1988:xviii). The stable place of the text (that is the Reports) is transformed into the dynamic space of Idriess' writing (Drums of Mer).

In the active reading and representation of the novel Yam Island people can be seen to be tactically appropriating the place of the text and utilising their own spatial practice, story-telling. If we understand narration not to be about approaching a reality as closely as possible, but of creating a fictional space which pretends to escape our present conditions (de Certeau 1988), then this Torres Strait Islander detour by way of a past via a story, can be understood as a means by which Yam Island people are actively producing powerful images of themselves.

Drums of Mer is by no means a great work of literary merit, but then nor are the Cambridge Reports. It is in combining fiction with his 'boy's own' style of presenting a particular past in the Torres Strait, that Idriess surpasses Haddon et al. in evoking an enthusiastic Torres Strait Islander response. It is in the fact that Kebisu, the iconic leader of Yam-Tudu, and others are named and are thus brought into existence, that the novel in many ways speaks to and not about Yam Islanders' knowledge of their past. In so doing it invokes/provokes particular narrative memories. Finally this is woven into a coherent yet highly romanticised story in which people are accurately located in place and time, and it is this which gives Drums of Mer as a novel a heightened orthodoxy and authority.

While I am not suggesting that Drums of Mer and the Reports of the Cambridge Anthropological Expedition to the Torres Straits are equivalent anthropological texts (see Kahn 1995), nor that one is reducible to the other, I have argued that it is in attending to the way in which Idriess recounts a tale (yan stori) and its resonance with story-telling practices on Yam Island, that the continuing appeal and impact of Drums of Mer for Torres Strait Islander readers can be more fruitfully approached and understood. As the

11. Two very well known 19 th century castaways and residents in the region were Barbara Thompson and the notorious Wini. 
quote from Said anticipated at the beginning of this paper, Yam Island people are able to 'assert their own identity and the existence of their own history' through this particular story. Unlike the Reports, this novel is a sensual rendering of a Torres Strait past, and at this level it operates on the imagination and through the senses. This Torres Strait Islander detour by way of a past via a story, in this case the regular referral to Drums of Mer, can be understood as one of inumerable means by which the Yam Island people continue to actively produce powerful images of themselves, for both themselves and for others. For as Feldman has so cogently stated, 'The event is not what happens . . . [but] that which can be narrated' (Feldman 1991:14).

\section{References}

Aboriginal and Islander Dance Theatre. 1996. Drums of Mer Program.

Barker, A. 1993. George Robertson: A Publishing Life in Letters. St. Lucia: University of Queensland Press.

Beckett, J. R. 1987. Torres Strait Islanders: Custom and Colonialism. Cambridge: Cambridge University Press.

Bhabha, H. 1984. Of Mimicry and man: The ambivalence of colonial discourse. October 28: 125-33.

de Certeau, M. 1988. The Practice of Everyday Life. Berkeley: University of California Press.

Dixon, R. 1996. Playing Tarzan: Australian photography and travel writing about Melanesia, 19201945. Australian Journal of Art 13:133-43.

Elvey, B. 1995. Ion Idriess. Sydney: Imprint.

Feldman, A. 1991. Formations of Violence: The Narrative of the Body and Political Terror in Northern Ireland. Chicago: University of Chicago Press.

Fitzpatrick-Nietschmann, J. 1980. Another Way of Dying: The Social and Cultural Context of Death in a Melanesian Community, Torres Strait. PhD Thesis, University of Michigan, Ann Arbor.

Foster, D. (ed.) 1991. (1974) Ion Idriess-self-portrait. In Self Portraits. pp.74-81. Canberra: National Library of Australia.

Fuary, M. M. 1991. In So Many Words: An Ethnography of Life and Identity on Yam Island, Torres Strait. PhD Thesis, James Cook University, Cairns.

Fuary, M. M. 1992. Torres Strait and Dawdhay: Dimensions of self and otherness on Yam Island. Paper presented to the Australian Anthropological Association Conference, Canberra, 30 Sept-2 Oct.

Fuary, M. M. 1993. Torres Strait cultural history. In N. Loos and T. Osanai, (eds). Indigenous Minorities and Education: Australian and Japanese Perspectives of their Indigenous Peoples, the Ainu, Aborigines and Torres Strait Islanders, pp.165-86. Tokyo: Sanyusha.

Gottlieb, A. and P. Graham. 1993. Parallel Worlds: An Anthropologist and a Writer Encounter Africa. Chicago: University of Chicago Press.

Haddon, A. C. et. al. (1971) 1904. Reports of the Cambridge Anthropological Expedition to Torres Straits. vol. v: Sociology, Magic and Religion of the Western Islanders. Cambridge: Cambridge University Press. 
Haddon, A. C. et. al. (1971) 1908. Reports of the Cambridge Anthropological Expedition to Torres Straits. vol. vi: Sociology, Magic and Religion of the Eastern Islanders. Cambridge: Cambridge University Press.

Haddon, A. C. et. al. (1971) 1912. Reports of the Cambridge Anthropological Expedition to Torres Straits. vol. iv: Arts and Crafts. Cambridge: Cambridge University Press.

Haddon, A. C. et. al. (1971) 1935. Reports of the Cambridge Anthropological Expedition to Torres Straits. vol. i: General Ethnography. Cambridge: Cambridge University Press.

Harrison, S. 1993. The Mask of War: Violence, Ritual and the Self in Melanesia. Manchester: Manchester University Press.

Idriess, I. (1933) 1941. Drums of Mer. Sydney: Angus and Roberstson.

Kahn, J. 1995. Culture, Multiculture, Postculture. London: Sage.

Kiernan, B. 1988. Perceptions of Australia, 1915-1965. Australian Literary Studies 13 (4): 269-83.

Macfarlane, Rev. W. H. 1941. Forword to I. Idriess, Drums of Mer. Sydney: Angus and Robertson,

Nile, R. and D. Walker. 1988. Marketing the literary imagination. Australian Literary Studies 13 (4):284-302.

Palsson, G. 1994. Introduction: Beyond boundaries. In G. Palson (ed.) Beyond Boundries: Understanding, Translation and Anthropological Discourse, pp.1-40. Oxford: Berg.

Roderick, C. 1947. 20 Australian Novelists. Sydney: Angus and Robertson.

Ruhen, O. 1979. Frontiersman with a pen. Australian Book Review September: 30-1.

Said, E. 1994. Culture and Imperialism. London: Chatto and Windus.

Sharp, N. 1996. No Ordinary Judgement: Mabo, The Murray Islanders' Land Case. Canberra: Aboriginal Studies Press.

Shoemaker, A. 1992. Black Words White Page: Aboriginal Literature 1929-1988. St. Lucia: University of Queensland Press.

Strathern, M. 1987. Out of context: The persuasive fictions of anthropology. Current Anthropology 28 (3): $251-81$.

Taussig, M. 1991. Mimesis and Alterity: A Particular History of the Senses. New York: Routledge.

White, H. 1973. Metahistory: the Historical Imagination in Nineteenth Century Europe. Baltimore: Johns Hopkins University. 